\title{
А.Ю. Рощупкин
}

\section{ЕЛЕЦКАЯ КРЕПОСТЬ НА ЮЖНЫХ РУБЕЖАХ МОСКОВСКОГО ГОСУДАРСТВА В КОНЦЕ ХVI - ПЕРВОЙ ПОЛОВИНЕ ХVII В. (СТРОИТЕЛЬСТВО, ВОССТАНОВЛЕНИЕ, РЕКОНСТРУКЦИЯ)}

\begin{abstract}
Статья посвящена рассмотрению ключевых моментов из истории елецкой крепости, связанных с изучением особенностей ее строительства в конце XVI в., а также характеристикой проведенных ельчанами работ по восстановлению и реконструкции города и укреплений в течение первой половины XVII в. В связи с этим основная цель исследования заключается в характеристике перечня работ, проводимых елецкими служилыми людьми во время строительства Ельца, а также в определении основных пунктов, характеризующих боеспособность крепости в периоды ее восстановления.

Ключевые слова: южные рубежи; елецкая крепость; служилые люди; елецкий гарнизон; городские и острожные укрепления; вестовой колокол; колодезные работы.
\end{abstract}

В летописных источниках первое упоминание о Ельце относится к 1146 г. Через несколько веков в 1395 г., город был разрушен после нашествия войск Тимура (Тамерлана). Окончательно Елец был уничтожен в начале XV в. после очередного набега татар [1. С. 4]. В состоянии запустения эти места пребывали вплоть до конца XVI в., когда в рамках политики Московского государства по укреплению стратегических позиций на южном направлении и защите центральных уездов от степной агрессии на берегах р. Быстрой Сосны началось строительство елецкой крепости [2. С. 23].

B XVII в. на фоне продолжавшихся процессов по продвижению вглубь территории «Поля» продолжались функционирование и развитие одного из важных пунктов обороны, Ельца. В связи с этим в работе анализируются аспекты, связанные с процессами, происходившими при начальном строительстве Ельца. Описывается восстановление ельчанами разрушенных укреплений и городской инфраструктуры после прохода летом 1618 г. через Елец казаков гетмана П. Сагайдачного. Характеризуется состояние города и острога в связи с готовившимся походом к южным границам гетмана Конецпольского. Освящается работа над крепостными стенами и частью городских построек после того, как в середине XVII в. бо́льшая часть Ельца была уничтожена пожаром, совпавшим с известием о подготовке к вторжению в русские земли объединенных сил казаков гетмана Б. Хмельницкого и крымских татар. Поскольку последующие годы не были отмечены столь масштабными работами по восстановлению укреплений и города, поэтому выбор хронологических рамок обусловлен тем, что на обозначенном временном отрезке происходили важные события, повлиявшие на историю города и жизнь ельчан.

Совокупность приведенных фактов не только поможет раскрыть картину жизни елецкой крепости, но и даст возможность судить о схожих процессах в соседних городах региона, позволяя говорить о том, что строительство и восстановление крепостей на протяжении многих лет находилось в русле политики по поддержанию геополитической стабильности на южных границах.

Зимой 1591 г. к остаткам Елецкого городища начали приходить первые «новоприборные» служилые люди и «посошные» крестьяне. Первым воеводой строящейся крепости стал князь И.Д. Звенигородский. Вместе с ним на должность головы был назначен выборный тульский дворянин И.Н. Мясной. Процессом строительства города, острога и крепостных стен руководил опытный городовой мастер И. Катеринин [3. C. 151].

В первые месяцы возведения елецкой крепости основная масса строительных работ выполнялась специально привлеченными для этого «посошными» крестьянами. Свое название крестьяне получили в связи с тем, что их набирали с «сохи». С «сохи», как правило, нанимали по 7 человек [Там же. С. 62]. Для оплаты их труда государство выделяло от 10 до 13 руб. [Там же. C. 34, 62]. Из-за тяжести условий при строительстве Ельца и несвоевременной денежной выплаты «посошные» люди за 4 недели «до Петрова дня» разбежались из города [Там же. С. 34]. Помимо них строившуюся крепость самовольно покинул мастер И. Катеринин, вместе с которым ушли дедиловские плотники [Там же. C. 137]. На смену Катеринину в Елец был вызван тульский кузнец И. Горбун, но его пребывание в городе было недолгим, о чем в Посольский приказ сетовали ельчане [Там же. С. 101].

Город и острог были вынуждены достраивать, «переменяясь пополам», неквалифицированные в этом деле «новоприборные» казаки и стрельцы [Там же. C. 136]. Детям боярским «городовое дело» было велено не делать, пока они дворы не поставят и землю не распашут [Там же. С. 64]. Для скорейшего завершения крепостных работ головой И.Н. Мясным было принято решение о привлечении присланных для охраны елецких строителей, детей боярских из Тулы и Рязани, а также служилых казаков из Крапивны, Данкова и Михайлова. Данное решение было воспринято служилыми людьми как самоуправство головы, о чем они сообщи- 
ли в Москву [3. С. 56, 57, 61, 62]. Казаки и стрельцы своими силами были не в состоянии справиться с возложенным на них объемом работ, поэтому многие ельчане предпринимали попытки самовольной записи на службу в другие города [Там же. С. 46].

О факте привлечения к строительству города, острога, а также укреплений казаки и стрельцы в своих грамотах и челобитных писали в Посольский приказ. Елецким служилым людям удалось своими силами, без «посошных» людей достроить городовые башни, тарасы, поставить надолбы, выкопать ров вокруг города, а также приступить к сооружению тайника. Для этого ельчане провели подготовительные земельные работы, но они приостановились из-за отсутствия у них опыта в городовом деле. Тем не менее служилыми людьми были подготовлены «брусья и бревенья в тайник дубовые» [Там же. С. 33-35, 37-39].

Параллельно со строительством укреплений вокруг города начали появляться служилые слободы, которые формировались согласно принадлежности их жителей к той или иной служилой группе: полковых казаков, стрельцов, пушкарей и затинщиков [1. С. 36, 37]. На противоположном от крепости берегу р. Сосны, отдельно от других слобод, донскими казаками были возведены укрепления беломестной слободы [3. С. 124 $127,173]$. Центральной точкой казачьей слободы стала церковь святого Дмитрия Солунского [4. С. 101]. В то же время беломестные казаки не участвовали в строительстве елецкой крепости и острога (интересный факт, что беломестная казачья слобода Ливен также располагалась напротив крепости «за рекою Сосною» [5. C. 56]. - A.P.). Кроме ельчан в городе строили дворы служилые люди из других городов. Так, для постоя в Ельце поставили свои дворы рязанцы и епифанцы на случай их приезда в город во время патрулирования смежных с ельчанами сторожей [3. С. 184, 186].

В ходе строительства крепости было множество дисциплинарных нарушений, возникали конфликты между служилыми людьми, а также между представителями местной власти и ельчанами. Из контекста таких дел становится ясно, что в Ельце с первых лет существования города была построена тюрьма, выполнявшая роль места содержания преступников до дальнейшего решения о выборе для них меры наказания [Там же. С. 151]. Для того чтобы служилым людям не оказаться в тюрьме, им необходимо было соблюдать ряд правил: беречь город от огня, татар и черкас, не воровать, не бражничать, жить смирно, а также ворота острожные запирать вовремя [Там же. С. 91, 160-162].

К осени 1592 г. часть крепостных сооружений была построена, а в Елец начали присылать вооружение, железо и церковную утварь. В ноябре в церковь Успения Пречистой Богородицы были привезены «образа и колокола», а в придел Великомученицы Ирины - богослужебные книги [Там же. С. 152]. В марте 1593 г. из Тулы и Новосиля были посланы пушки, ядра, пищали, зелье (порох) и свинец [Там же. С. 68, 69]. Из Новосиля оружие сопровождали стрелецкий сотник Д. Болотов и отряд из 50 казаков [Там же. С. 68]. Пушки должны были усилить огневую мощь крепости. Пищали, вероятно, предназначались для выдачи тем казакам и ратным людям, у которых они отсутствовали. В это же время из Тулы в Елец были направлены подводы с колоколом и железом в сопровождении «добрых» пушкарей и кузнеца взамен сбежавшего И. Горбуна [Там же. С. 179].

После завершения строительных работ по возведению оборонительных укреплений и формированию вокруг крепости служилых слобод ельчане были привлечены правительством к обработке десятинной пашни, что должно было ускорить освоение земельного фонда и формирование границ будущего Елецкого уезда [6. С. 241]. Помимо этого, ельчане выполняли обязанности по несению сторожевой и станичной службы, патрулированию окрестностей вокруг крепости, нахождению в дозоре по периметру городских стен, а также по поддержанию порядка внутри служилого гарнизона. За первое десятилетие после строительства Ельца никаких работ по укреплению городовых стен или перестройке ее отдельных участков ельчанами не проводилось. В таком состоянии город подошел в 1604 г. к событиям Смутного времени. В первые месяцы продвижения Лжедмитрия I по северским землям елецкий гарнизон поддерживал Б. Годунова. После присоединения к самозванцу многих русских городов ельчане заняли антиправительственную позицию, поддержав «законного» царя. После убийства Лжедмитрия I правителем стал В. Шуйский. Однако елецкие служилые люди не признали нового царя, в результате летом 1606 г. к Ельцу были посланы войска под руководством князя И.М. Воротынского, которые взяли город в осаду. Многомесячное противостояние города с правительственными силами не имело негативных последствий для елецких укреплений [7. С. 42, 85, 117, 156]. В первые годы царствования М.Ф. Романова произошло столкновение интересов новой царствующей династии с польской короной в лице королевича Владислава, что привело к проходу через ряд русских уездов многочисленного войска гетмана П. Сагайдачного. Это трагическое событие в истории Ельца принесло городу не только огромные людские потери, но и частичное разрушение елецких укреплений [8. С. 127132, 219, 235, 239; 9].

Первым воеводой в Ельце после прохода запорожских казаков стал Г.Л. Валуев [10. Л. 117]. По прибытию в город им были определены степень разорения елецкого острога, служилых слобод, численность выживших служилых людей, наличие гужевого транспорта, остатки оружия, а также возможности обороны крепости тем «нарядом», который был в его распоряжении. Руководствуясь собранным материалом, воевода отправил в Москву подробный отчет, под которым подписались наиболее авторитетные елецкие дети боярские [Там же. Л. 128, 129]. 
Из отчета воеводы следует, что в Ельце не было необходимого количества оружия и припасов для несения службы. В случае внезапного прихода татарских или черкасских отрядов ельчане оказались бы беспомощны. Им «не с чем и оборониться от воинских людей, и зелья и свинцу на Ельце мало» [10. Л. 132]. Крепостная артиллерия также находилась в плачевном состоянии. Пушки были забиты камнями, и стрелять из них «было немочно» [Там же. Л. 120]. Даже в случае их частичной починки использование как эффективного оборонительного вооружения было сведено к минимуму за счет того, что не было достаточного количества пороха. Для восстановления елецкого «наряда» и раздачи служилым людям необходимых запасов 17 марта из Москвы в Елец прибыл обоз с Осипом Тороповым. Им были привезены три больших железных пищали, 50 пудов пороха и 25 пудов свинца [Там же. Л. 142].

Перед началом строительных работ по возведению разрушенных частей елецкой крепости встал вопрос о месте строительства. Напротив остатков укреплений Г.Л. Валуев обратил внимание на левый берег р. Елец, где располагалась высокая Аргамачья гора. Несмотря на удачное расположение выбранного воеводой места, возникла проблема со снабжением будущей крепости водой, а также о тяжести проведения земельных работ. Поскольку при копке колодцев и рва ельчане наткнулись на камень, было принято решение о строительстве на старом месте [Там же. Л. 119].

По планам Г.Л. Валуева, новая крепость вместе с башнями и воротами должна была равняться 750 саженям [Там же. Л. 138]. Елецкие служилые люди, так же как и в 1592 г., приступили своими силами к строительству крепостных сооружений. Ельчанам предстояло поставить острог, башни, тарасы, дворы и острог окопать рвом [Там же. Л. 136]. Если проблемы, связанные с нехваткой лошадей и заготовкой строительного материала, служилые люди решали собственными силами, то вопросы, касающиеся поиска воды и изготовления вестового колокола, потребовали обращения в Москву.

На чертеже, сделанном Валуевым, значились два места под колодцы. Одно находилось между церквями Михаила Архангела и Пятницкой, другое - между Новосильских и Ливенских ворот. Однако поиски ельчан не увенчались успехом, так как «воды ныне в остроге нет, а опричь тех мест, что в чертеже, колодцы копать негде». Так как вода была очень важна при осаде крепости, то строители попробовали прокопать тайник к реке Сосне, но из-за большого расстояния до водоема им это сделать не удалось. На помощь служилым людям из Москвы были направлены два колодезных мастера [Там же. Л. 139].

Наличие в городе вестового колокола было необходимым условием для своевременного реагирования служилых людей в случае опасности. Для его изготовления планировалось использовать имеющиеся в елецких храмах и церквях колокола. После осмотра собор- ной Воскресенской церкви, церкви Николая Чудотворца и храма Михаила Малеина оказалось, что колоколов нет. Заняться отливом нового колокола Г.Л. Валуев поручил кузнецу Антону Иевлеву [Там же. Л. 143]. В силу того, что в распоряжении мастера не оказалось нужного количества меди и олова, работа была отложена до указания из Москвы. К апрелю 1619 г. большая часть Ельца была восстановлена.

С каждым годом состояние елецких укреплений ухудшалось. Без надлежащего осмотра и ухода деревянные стены, башни и постройки подгнивали, что в итоге приводило к их частичному разрушению. От этого напрямую зависели обороноспособность крепости и защита населения города и уезда. Заступавшие на службу в Елец воеводы обращали внимание на ветхое состояние укреплений, однако никаких мероприятий по ремонту в течение многих лет не предпринимали. Это было связано с отношением представителей царской администрации к выполнению своих обязанностей в новом городе. Как правило, сроки их воеводства были небольшие, поэтому те не хотели себя обременять организацией строительства и привлечением служилых людей, которые сами всячески старались от этого уклониться.

Плохое состояние елецкой крепости детально характеризует грамота прибывшего в 1639 г. в Елец воеводы Федора Алябьева [11. С. 112, 113]. Со временем его воеводства была связана новость о предстоящем походе гетмана Конецпольского «под украйные города». При подготовке Ельца к обороне Алябьев столкнулся с проблемой готовности острога и укреплений к возможной осаде. Со слов воеводы в Ельце «города рубленного нет, а поставлен в городе дубовый острог». В остроге находилось 4 ворот и 7 башен глухих. Перед острогом был выкопан неглубокий ров, который не был укреплен тыном и не были поставлены надолбы. Во многих местах «острожные стены худы», часть из них обвалилась, причиной этому Алябьев называет то, что «поставлен тот острог в давних летах». Состояние башен также было малопригодным для ведения осады. Ливенская башня обвалилась по углам, две угловые башни «худы, низки и ветхи». Кроме этого, необходимых для обороны крепости огнестрельного оружия и запасов для него было явно недостаточно [Там же. С. 113].

С течением многих лет так и не был решен вопрос с обеспечением острога нужным количеством воды. В самом остроге колодца не было. Он был выкопан в 17 саженях от укреплений по направлению к реке Сосне. Для защиты колодца над ним была поставлена башня с бойницами. Однако это не решало существующей проблемы с водой, поскольку ее было недостаточно и «в приход больших воинских людей в приступное время воды будет скудно».

Важным элементом оповещения жителей города об опасности был вестовой колокол, который находился на Васильевских воротах. Если Г.Л. Валуев при восстановлении Ельца столкнулся с отсутствием в 
городе колокола, то Алябьев отметил, что колокол мал и «в всполошное время звон слышен мало» [11. С. 113].

При этом елецкая крепость не только не имела надежной обороны, но и гарнизон был ослаблен многочисленными государевыми службами. Часть служилых людей была переведена «на житье» в новые города: Козлов, Тамбов, Ефремов, в Талецкий и Чернавский остроги. Многие ельчане были посланы для строительства в Яблонов, Усерд, также для восстановления Талецкого и Чернавского острогов. На место покинувших Елец служилых людей должны были прибыть «прибавочные люди из Рязани и из иных городов», но никто в город не приехал.

В ответ на челобитную Ф. Алябьева было дано указание летом начать подготовку необходимого для строительных работ материала. По зимнему пути ельчане должны были доставить его к городу, а весной 1640 г. приступить к реконструкции укреплений и острога. Поскольку известия о походе литовских отрядов не подтвердились, отправить в Елец недостающее количество «снаряду и зелья» было решено только зимой.

Плохое состояние укреплений и острога было характерно не только для елецкой крепости, такая ситуация наблюдалась и в других русских городах. Так, например, воевода Дементий Хлопов писал, что в Козельске все укрепления сгнили и «разваливаются», а рвы вокруг острога осыпаются. В остроге практически не было воды. Из двух колодцев один был пуст. Служилых людей в Козельске для осадного сидения было недостаточно. Многие из них были без пищалей, а у которых они есть, те «худы и коротки» [12. Л. 242-244].

В июле 1648 г. в Ельце случился крупный пожар, который уничтожил не менее 230 сажень елецких укреплений [3. С. 112]. Восстановление сгоревшей части крепости проходило медленно, пока А.В. Хрущева на посту елецкого воеводы не сменил Алексей Васильевич Бутурлин. А.В. Бутурлин приехал на службу в Елец в середине июля 1649 г. Воевода определил состояние елецких укреплений и пришел к выводу, что «города и острогу нет, а зелейная и свинцовая казна, наряд и житницы десятинных хлебов стоят без крепостей» [13. Л. 201]. Служилый гарнизон был практически небоеспособен. Из тех казаков и стрельцов, кто находился в городе, часть была безоружна, а у тех, кого были пищали, они были «худы» [Там же. Л. 203].

Бутурлин, так же как и Г.Л. Валуев 30 лет назад, оценил перспективу переноса города на Аргамачью гору. Для строительства укреплений на новом месте воеводой был организован сбор елецких служилых людей. Ими был найден в 30 верстах от Ельца пригодный для городового дела лес. С помощью уездных и городовых людей его удалось «с поспешанием» привезти к Аргамачьей горе. Из подготовленных бревен ельчане смогли заложить четыре угловых башни и укрепить посад [Там же. Л. 202].

В начале осени 1649 г. в русские города начали поступать сообщения об активности черкасских казаков на русско-польской границе и их сборе в г. Зеньков. В 20-х числах сентября от ливенского воеводы Якова Кологривова Бутурлину было прислано известие о готовящемся вторжении. Согласно сведениям осенью и по зимнему пути объединенное войско гетмана Богдана Хмельницкого и крымских татар должно было выступить к «украинным» городам. В связи с этим елецким служилым людям было послано указание быть готовым к «сходу в Белгород». Ельчане отправились по домам для подготовки лошадей и запасов, после чего строительство города на Аргамачьей горе приостановилось [Там же. Л. 202].

В октябре из Путивля пришла новая информация о предстоящем походе гетмана и крымских царевичей. В Ельце воеводе А.В. Бутурлину было «велено город делать наспех» [Там же. Л. 204]. Поскольку продолжение строительства новой крепости требовало значительных сил, воевода вернулся к восстановлению старых укреплений. Вероятно, для выполнения строительства Бутурлин использовал приготовленные ранее материалы на Аргамачьей горе и части заложенных башен. Судя по документам, Бутурлину удалось в кратчайшие сроки «устроить город со всеми крепостями», поэтому «ему в сход ходить не велено», а тех служилых людей, которые успели отправиться в Белгород, вернули в Елец к прежним местам [Там же. Л. 205, 206].

Таким образом, рассмотренные в статье процессы строительства, восстановления и реконструкции елецкой крепости позволили нам сказать, что все мероприятия, связанные с работами по поддержанию в боеготовности городских и острожных укреплений, проводились в рамках потребности государства по усилению южных рубежей, а также по сохранению на протяжении многих лет их целостности. Все работы по строительству и восстановлению укреплений ложились на плечи служилых людей елецкого гарнизона, выполнявших их параллельно с несением «государевой» службы по охране и патрулированию уезда и смежных территорий. Плановых мероприятий по частичной переделке укреплений и восстановлению разрушавшихся в течение многих лет участков крепостных стен приезжавшими в Елец воеводами не проводилось. Тем не менее воеводы из стратегических соображений рассуждали о местоположении построенной крепости и вносили предложения по ее переносу на новое место. Однако в силу внутренних и внешних обстоятельств ни одному из воевод не удалось осуществить намеченные планы. При этом вопросы по комплектованию вооружением служилых людей, обеспечение гарнизона водой, а также восстановление системы оповещения решались воеводами в кратчайшие сроки. 


\section{ЛИТЕРАТУРА}

1. Ляпин Д.А. История Елецкого уезда в конце XVI-XVII вв. Тула : Гриф и К, 2011. 208 с.

2. Буганов В.И. Разрядная книга 1475-1605 гг. М. : Институт истории АН СССР, Наука, 1989. Т. III, Ч. III. 152 с.

3. Глазьев В.Н., Новосельцев А.В., Тропин Н.А. Российская крепость на южных рубежах. Документы о строительстве Ельца и заселении окрестностей в 1592-1594 гг. Елец : ЕГУ им. И.А. Бунина, 2001. 274 с.

4. Котков С.И. Памятники южновеликорусского наречья. Конец XVI-XVII в. М. : Наука, 1990. 170 с.

5. Пясецкий Г.М. Исторические очерки города Ливен и его уезда в политическом, статистическом и церковном отношении / под ред. А.П. Олейниковой. Орёл, 1999. 208 с.

6. Платонов С.Ф. Очерки по истории Смуты в Московском государстве XVI-XVII вв. СПб., 1910. 624 с.

7. Белокуров С.А. Разрядные записи за Смутное время (7113-7121 гг.). М. : Типография штаба Московского военного округа, 1907.311 с.

8. Документы российских архивов из истории Украины. Львов, 1998. Т. І. Документы по истории запорожского казачества $1613-1620$ гг. 440 с.

9. Российский государственный архив древних актов (РГАДА). Ф. 210. Оп. 13. Столбцы Приказного стола. Д. 5.

10. РГАДА. Ф. 210. Оп. 10. Столбцы Владимирского стола. Д. 7.

11. Акты Московского государства. Том II. Разрядный приказ. Московский стол. 1635-1659 гг. / под ред. Н.А. Попова. СПб. : Типография Императорской Академии наук, 1894. 773 с.

12. РГАДА. Ф. 210. Оп. 12. Столбцы Белгородского стола. Д. 142.

13. РГАДА. Ф. 210. ОП. 12. Столбцы Белгородского стола. Д. 317.

Roschupkin Alexey Yu. Yelets state university of I.A. Bunin (Yelets, Russia). E-mail: alex.roschupkin@rambler.ru

YELETS FORTRESS AT THE SOUTHERN BOUNDARIES MOSCOW STATE AT THE END TO THE XVI FIRST HALF OF THE 17 TH CENTURIES. (CONSTRUCTION, RESTORATION, RECONSTRUCTION).

Keywords: southern boundaries; Yelets fortress; sluzhily people; Yelets garrison; city and ostrozhny strengthenings;

The main objective of the article consists in the characteristic of the list of works as the carried-out by Yelets service class men during construction of Yelets, and also in allocation of the main points defining fighting capacity of fortress during recovery work. In this regard the tasks in which separate episodes from fortress history found reflection were set. It is necessary to give the characteristic to city building, a fortress and fortifications in 1591-1653, to reveal the problems which arose at the service class men and also to define fighting capacity of Yelets garrison during this period. Secondly, to consider restoration in 1619 under the leadership of the voivode G.L. Valuyev of Yelets fortification after pass on the southern counties in the summer of 1618 of Cossacks of the hetman P. Sagaydachny. Thirdly, to analyze the process of carrying out reconstruction of a part of fortifications organized in connection with news of the being outlined campaign to the Russian borders in 1639 of army of the hetman S. Konetspolsky. Fourthly, to analyze the restoration of Yelets fortress after the fire in the middle of 17th century. For completing the designated tasks, rare documents from Russian State Archives of Ancient Documents funds, a part from which was published, were attracted, and a part is for the first time introduced for scientific use. On their basis the author managed to track how the geopolitical situation at the southern boundaries affected the processes connected with construction works. After the analysis of the available documents the author came to the following conclusions. All actions connected with works on maintenance in combat readiness of city and fortress fortifications were held within need of the state on strengthening of the southern boundaries. Works on construction and restoration of fortifications laid down on shoulders of the service class men of Yelets garrison who were carrying out them in parallel with execution of "monarchic" service. Planned actions for partial alteration of fortifications and restoration of the sites of defensive walls collapsing for many years, by the voivodes coming to Yelets were not carried out. For strategic reasons the opinion on transfer of fortress on the new place moved forward.

\section{REFERENCES}

1. Lyapin, D.A. (2011) Istoriya Eletskogo uezda v kontse XVI-XVII vv. [The history of Eletsk County in the late 16th - 17th centuries]. Tula: Grif i K.

2. Buganov, V.I. (1989) Razryadnaya kniga 1475-1605 gg. [Statutory Acts of 1475-1605]. Vol. 3. Moscow: Nauka.

3. Glaziev, V.N., Novoseltsev, A.V. \& Tropin, N.A. (2001) Rossiyskaya krepost' na yuzhnykh rubezhakh. Dokumenty o stroitel'stve El'tsa i zaselenii okrestnostey v 1592-1594 gg. [A Russian fortress on the southern borders. The documents on the construction of Elets and neighborhood settlement in 1592-1594]. Elets: Elets State University.

4. Kotkov, S.I. (1990) Pamyatniki yuzhnovelikorusskogo narech'ya. Konets XVI-XVII v. [Monuments of the South Russian dialect. The late 16th 17th centuries]. Moscow: Nauka.

5. Pyasetskiy, G.M. (1999) Istoricheskie ocherki goroda Liven i ego uezda v politicheskom, statisticheskom i tserkovnom otnoshenii [Historical descriptions of the city and county Lieven in the political, statistical and church relations]. Orel: Orel State Tele-and-Radio Company.

6. Platonov, S.F. (1910) Ocherki po istorii Smuty v Moskovskom gosudarstve XVI-XVII vv. [Essays on the History of the Troubles in the Muscovite state in the 16th -17 th centuries]. St. Petersburg: M.A. Aleksandrov.

7. Belokurov, S.A. (1907) Razryadnye zapisi za Smutnoe vremya. (7113-7121 gg.) [Statutory Acts for the Time of Troubles.(7113-7121 gg.)]. Moscow: Moscow Military District.

8. Dokumenty rossiyskikh arkhivov iz istorii Ukrainy [The documents of the Russian archives of the history of Ukraine]. (1998) Vol. 1. Lvov.

9. The Russian State Archives of Ancient Documents (RGADA). Fund 210. List 13. File 5.

10. The Russian State Archives of Ancient Documents (RGADA). Fund 210. List 10. File 7.

11. Popov, N.A. (ed.) (1894) Akty Moskovskogo gosudarstva [Acts of the Muscovite state]. Vol.2. St. Petersburg: Imperial Academy of Sciences.

12. The Russian State Archives of Ancient Documents (RGADA). Fund 210. List 12. File 142.

13. The Russian State Archives of Ancient Documents (RGADA). Fund 210. List 12. File 317. 